Indexaciones: Repositorio de Revistas UCR, DIALNET, Latindex, REDALYC Directorio y recolector de recursos digitales del Ministerio de Cultura de España, Directory of Open Access Journals. Diálogos Revista Electrónica de Historia ISSN 1409- 469X. Número especial 2008. Dirección web: http://historia.fcs.ucr.ac.cr/dialogos.htm

\section{Control del poder y exclusión de competidores: La decisión constitucional para establecer el servicio civil en Costa Rica.}

\section{M.B.A. William Elizondo Calderón.}

Correo electrónico welizondoc@yahoo.com.mx. Funcionario de la Dirección General de Servicio Civil y Profesor de la Escuela de Estudios Generales de la Universidad de Costa Rica. 


\section{Introducción}

Con la Constitución Política emitida el 7 de noviembre de 1949 inicia a regir y llevarse a la práctica un conglomerado institucional, requerido para dar soporte al estilo de desarrollo que profundizaría el esquema capitalista iniciado desde el siglo XIX. Este instrumento jurídico sería un apoyo para la emergencia al poder político de los sectores sociales que, desde hacía décadas, propugnaban por abrirse paso frente a las limitaciones del liberalismo mantenido por la oligarquía cafetalera en asocio con el capital extranjero.

Con ella se crearon o consolidaron instituciones que se ocuparían de aspectos económicos, de infraestructura y energía, con el fin de apoyar los procesos productivos. Otras tendrían un carácter social, para asegurar una base sólida de respaldo político para los nuevos detentadores del poder, además de la mano de obra con la calidad requerida, sustentada en programas de educación, salud, vivienda y bienestar social. En el mediano plazo ocurre una recomposición de la oligarquía, integrando a los nuevos sectores, y se fortalece el capitalismo como sistema económico social, lo que implicó mayor influencia del capital transnacional, ampliando el vínculo con las inversiones provenientes de Estados Unidos.

En este marco se inscribe la emergencia y consolidación del régimen de servicio civil, como parte de la modernización administrativa requerida, mediada por el aseguramiento del control sobre la organización de la administración pública del país. La ponencia que se presenta a este IX Congreso Centroamericano de Historia, se enfoca en la discusión realizada durante la Asamblea Nacional Constituyente de 1949, que amplió el rango constitucional del servicio civil.

El control de la composición ideológica y política del cuerpo de servidores públicos, sería una consecuencia de las condiciones existentes luego de la guerra civil librada entre marzo y abril de 1948. La consolidación en sus puestos de un cuerpo de funcionarios leales y comprometidos, no tanto ni de manera conciente con el nuevo estilo de desarrollo, pero sí con sus impulsores, sería uno de los resultados de esta estrategia, justificada con el discurso sobre la necesidad de profesionalización de la administración pública.

El ejercicio del control ideológico sería el complemento de la exclusión de los opositores derrotados durante el conflicto armado, quienes durante varios lustros fueron marginados del acceso a la función pública. Para esto se utilizaron diversos mecanismos como: el despido de la función pública sin el pago de los derechos laborales vigentes y casi de manera inmediata a la asunción del poder por la Junta Fundadora de la Segunda República; uso ideológico de 
calificativos que los desvalorizaban como actores sociales, mediante acusaciones públicas de malversadores de fondos públicos y ejecutores del fraude electoral; exilio de sus líderes principales; creación de mecanismos legales para favorecer a los participantes en el bando de los triunfadores durante el conflicto armado. Además continuaron las prácticas de compadrazgo y favorecimientos personales.

Asegurarse que dentro del aparato estatal se mantuviera un conjunto de personas afines con la forma de pensamiento y los objetivos políticos de las nuevas fuerzas sociales y políticas, se constituyó en un mecanismo para mantener el ejercicio del poder durante los períodos temporales de reflujo. Asimismo garantizó que quienes fueron relegados no lograran una cuota importante de control en las decisiones de los asuntos públicos, por lo que no serían una fuente de conflicto y menos de oposición para los fines de los triunfadores.

El ejercicio del poder se convirtió en una herramienta para reafirmar la calidad de triunfadores frente a los perdedores, desconociendo el logro de quienes fueron desplazados, al menos temporalmente.

Lo señalado pretende una explicación del surgimiento del servicio civil, sin menoscabar la importancia de esta institución, que al mantenerse y desarrollarse a lo largo de muchas décadas, se constituye en parte del sistema democrático que, en el marco del estilo que hemos mencionado, es garante del acceso a la función pública mediante mecanismos de concurso público, al que cualquier persona puede acceder de acuerdo con sus condiciones y atestados. Es además el referente más importante para la administración de personas en el sector público costarricense, que incluye procedimientos de reclutamiento y selección, aplicando pruebas en igualdad de condiciones para todos los participantes, salarios similares en puestos similares, carrera administrativa y programas de capacitación, entre otros procesos técnicos especializados.

Como entidad técnica de la función pública, el servicio civil requirió una conceptualización para establecerse, así como un proceso de generación de su demanda, como necesidad para el desarrollo de la administración pública del estado. En la costumbre de los cambios en la composición de los funcionarios públicos que acompañaban cada cambio de gobierno, no era concebible que tales empleados no pudieran ser reemplazados por otros afines con los nuevos gobernantes. En tal sentido la decisión de crear esta institución no solo es resultado de la buena voluntad o iluminación de un sector muy avanzado de diputados constituyentes, sino parte de un proceso gestado desde décadas anteriores, pero que además continúa luego de 1949. La Asamblea 
Constituyente no da fin a su configuración, sino que marca los enunciados fundamentales por los que continúa su vida institucional hasta la actualidad.

Para la realización del estudio se recurrió a las actas de la Asamblea Constituyente, así como a otros documentos disponibles en la página electrónica "El Espíritu del 48”. El análisis ocurre en el marco de las interpretaciones sobre la década de 1940 y del nuevo estilo de desarrollo que ocurre a partir de la constituyente de 1949 y la emergencia de los actores políticos que pasan a ser parte de la oligarquía. El discurso de los triunfadores en el marco constitucional señala los fines del servicio civil, así como la exclusión de que fueron objeto quienes resultaron perdedores del proceso, lo que explica su instrumentación para el ejercicio y control del poder.

A continuación se presentan los aportes más importantes de la discusión de los diputados constituyentes, que en 1949 tuvieron entre sus temas el mantenimiento o no del servicio civil, las motivaciones y manifestaciones sobre la administración de los recursos públicos, así como el uso político y administrativo: como instrumento para el logro de determinados objetivos por parte de los gobernantes.

\section{Antecedentes inmediatos de la reforma constitucional de 1949:}

Mediante la ley $\mathrm{N}^{\circ} 540$ de 18 de junio de 1946, por iniciativa de diez diputados de oposición se reformó la Constitución Política vigente desde 1871, estableciendo el régimen de servicio civil al disponer entre las atribuciones del Presidente de la República lo siguiente:

“Artículo 109. Son deberes y atribuciones del Poder Ejecutivo:

$1^{\circ}$. Nombrar y remover libremente a los Secretarios de Estado, a los funcionarios y empleados diplomáticos, a los militares y a los otros que indique el Estatuto Civil de la Función Pública y, con sujeción a las prescripciones de este, a los demás funcionarios y empleados de su dependencia. Para la aprobación o enmienda de dicho Estatuto se necesitará el voto de los dos tercios de la totalidad de los miembros del Poder Legislativo y en el no podrá incluirse como impedimento para la admisión al ejercicio de la función pública, ni como causal de destitución, el hecho de sustentar determinadas ideas de carácter político o social.”

Este antecedente no fue producto de una ocurrencia, situación coyuntural, o la simple voluntad de los diputados de entonces. Entre la opinión pública y los actores políticos nacionales existía conciencia de la necesidad de una administración pública profesionalizada. La herencia ilustrada 
de la Constitución de 1825 proclamaba el derecho de los ciudadanos para ejercer la función pública sin otra diferencia que la de sus méritos. Más reciente sería la conocida frase de don Ricardo Jiménez, pronunciada en su mensaje al Congreso en 1928:

“... Nombramientos hechos basándose en política partidista resultan pésimos. Tiempo es ya de establecer el Servicio Civil: pruebas de competencia y ascensos por méritos comprobados en el Servicio. Hay que desarraigar la idea de que los cambios de gobierno se hacen para cambiar el disfrute de sinecuras...”

La frase criticaba a los políticos de entonces, quienes como gamonales en sus feudos distribuían favores, prebendas y puestos entre los colaboradores de las campañas electorales. Había quienes, como Don Ricardo, consideraban tales prácticas como un mal necesario de erradicar. En el contexto de la época es posible que existiera un conflicto por la distribución de prebendas, no obstante revela que el concepto básico de la demostración de los méritos, que implicaba la creación del servicio civil ya era considerado necesario para el buen funcionamiento de la administración pública, al menos por una parte de quienes buscaban el ejercicio del poder político. Hacía pocos años que el Partido Reformista había proclamado entre sus propósitos al crearse en 1923:

"Ley de escalafón y estabilidad en ciertos ramos de la Administración Pública, a fin de preparar una administración Técnica y poner a salvo de la política las más importantes funciones administrativas". ${ }^{1}$

En ese contexto y en respuesta a la politiquería resultante de la dinámica con que funcionaban los partidos políticos personalistas de esas décadas, en 1931 el Partido Comunista incluyó como uno de sus objetivos programáticos de corto plazo emitir una ley de servicio civil. ${ }^{2}$ Por lustros sería el único partido que tendría tal meta dentro de su programa político, ya que el Partido Reformista se disolvió oficialmente en 1934.

Durante los años de 1940 la recurrencia a los conceptos sobre el servicio civil se amplió a otros sectores políticos. Los argumentos esgrimidos por los diputados constituyentes aludían las experiencias de otros países, así como al valor moral de opiniones altamente apreciadas en la coyuntura del momento, entre las que estaba la expresada en 1943 por el expresidente don León Cortés, entonces candidato presidencial por la oposición al calderonismo, proponiendo entre sus objetivos de gobierno la creación del servicio civil en los siguientes términos: 
"Con una ley de servicio civil, las campañas políticas perderían interés o finalidad de lucro, o en otros términos, en ellas no jugarían papel intereses utilitarios, de mejoramiento de condiciones personales, sino que sus actividades se levantarían sobre más altos y honestos postulados. No se entraría a las lides electorales con el anzuelo levantado para pescar posiciones del presupuesto bien remuneradas y con la oportunidad del turbión electoral. No se pretendería hacer méritos dentro de los viciados procedimientos de infamar y de calumniar, los cuales por desgracia, cada día toman mejor asiento en nuestras campañas políticas. Quien mantiene ese género de ideas con respecto a la reforma constitucional tan necesaria como depuradora de nuestros procesos electorales, no ha de vacilar en hacer promesa a sus conciudadanos de que llegando nuevamente al Poder, propiciaría y defendería la respectiva reforma constitucional para el implantamiento de una bien meditada ley sobre el servicio civil”?.

Precisamente para que no estuviera sujeta a los vaivenes políticos del momento, el Diputado Constituyente don Manuel González Herrán, quien había sido uno de los fundadores del Partido Socialdemócrata pero electo por el Partido Unión Nacional, curiosamente aludió al ejecútese por don León Cortés en 1936, a la derogatoria de una Ley de Servicio Civil que estuvo vigente en la Municipalidad de San José4. El Diputado González Herrán no criticaba el aparente discurso contradictorio del señor Cortés, quien fuera declarado Benemérito de la Patria por la Junta de Gobierno, sino que se sumaba a los socialdemócratas para defender la necesidad indispensable de que la Ley de Servicio Civil tuviera rango constitucional, lo que impediría decisiones como la que hizo recordar.

Otra opinión aludida y de gran relevancia por su atingencia en el mismo año 1943, es producto de la consulta que a manera de encuesta efectuó el "Grupo Coronas”, al indicar lo siguiente:

“... debe promulgarse una ley de Servicio Civil, adecuada para llenar cumplidamente las necesidades de los servicios oficiales y para ir formando una verdadera carrera de funcionarios públicos, en la cual todos los costarricenses tuvieran derecho de ingresar mediante la presentación de exámenes satisfactorios por oposición, de ascender por méritos, competencia y antigüedad, de mantenerse establemente en ella por causas dependientes exclusivamente por su idoneidad y del cumplimiento de sus obligaciones, $y$ de gozar de garantía plena en cuanto a su estabilidad en el escalafón, a una remuneración 
decorosa y suficiente para hacer frente a las necesidades pecuniarias de su vida, a su jubilación para la vejez y la incapacidad de trabajar, y a la pensión para su familia en caso de fallecimiento. Es claro que habría de exigirse a tales funcionarios competencia y probidad absolutas en el desempeño de sus funciones y en su vida privada, para lograr más cabalmente lo cual, sería necesario crear escuelas de preparación técnica para las diversas ramas de la administración pública, y un tribunal disciplinario encargado de velar por el fiel cumplimiento del servicio civil, por el correcto desempeño de los deberes de cada funcionario del Estado y por la adecuada sanción que habría de imponerse a quien no cumpliera sus obligaciones con eficiencia, actividad y honradez ..." .

Los enunciados anteriores no dejan dudas del conocimiento que sobre la materia se tenía en el país, así como los postulados principales que debería contener una ley de servicio civil. Podemos además observar aspectos que luego no fueron incluidos dentro del Estatuto emitido en 1953, como el derecho de los empleados públicos a la jubilación por vejez o por incapacidad para trabajar, el establecimiento del tribunal disciplinario, así como la necesidad de escuelas de capacitación técnica, aspectos que fueron desarrollados en lustros posteriores.

Se pueden indicar otros antecedentes de la década de 1940. El Partido Unión Nacional, del que en 1948 sería candidato don Otilio Ulate, incluyó la creación del servicio civil en su programa de gobierno al constituirse en 1946.

Las publicaciones del Centro para el Estudio de los Problemas Nacionales, enunciaban la necesidad de crear el servicio civil en el marco de un nuevo pensamiento político modernizador, aspiración que luego sería parte de los postulados programáticos del Partido Socialdemócrata, fundado en 1945 y autodefinido ideológicamente como socialista y democrático.

Don Oscar Barahona Streber, quien durante algunos años fuera miembro del Partido Comunista y luego muy cercano colaborador del Doctor Calderón Guardia y del Presidente de Guatemala don Juan José Arévalo, redactó el primer proyecto de Estatuto de Servicio Civil en 1945, antes de emitirse la reforma constitucional de 1946. Este documento durmió por unos años “el sueño de los justos”, pero sería un fundamento del Estatuto emitido en 1953, al punto que gran parte de su contenido fue transcrito casi literalmente?

El marco anterior nos permite señalar que la discusión en la Asamblea Constituyente, sobre el establecimiento del Servicio Civil en Costa Rica no estaba en terreno estéril, ni los propulsores 
(y oponentes) se encontraban en un marco conceptual desconocido. Tampoco lograron abstraerse de las demandas políticas imperantes, ni de las politiqueras, que fueron consustanciales al proceso, en mayor medida por la situación de transición del momento histórico y el afloramiento constante de contradicciones entre los sectores políticos que se disputaban los rumbos del país.

\section{La discusión de la Asamblea Constituyente y el servicio civil:}

En la Asamblea Constituyente los representantes del Partido Socialdemócrata eran minoritarios, pero tenían una base conceptual de la que carecían sus mayoritarios opositores. Los contenidos del proyecto de servicio civil incluido en la propuesta de Constitución Política presentado por la Junta gobernante, fue retomado e impulsado por esta fracción, integrada únicamente por cuatro diputados.

Las discusiones para decidir sobre este asunto tuvieron tres fases o momentos durante la definición del articulado constitucional: el primero ocurre al definirse las facultades del Poder Ejecutivo y determina la continuidad o no de la potestad de los nombramientos de los servidores de acuerdo con la ley de servicio civil. El segundo establece la fecha en que dicha ley debería ser emitida, que en realidad se define durante la misma discusión sobre la existencia o no de la mención constitucional y se materializa con el establecimiento de un transitorio. Este aspecto es relevante, por estar de por medio la estabilidad de los empleados nombrados durante el periodo de la Junta de Gobierno presidida por Don Pepe y la posibilidad de que don Otilio Ulate pudiera nombrar a sus copartidarios.

El tercer momento ocurre para incluir un Título Constitucional propio sobre el servicio civil, que vendría a ser el Título XIII. Hay un cuarto momento que retrae la discusión sobre la fecha de la emisión de la ley de servicio civil, que revisa el texto del transitorio y le agrega un párrafo adicional, que ocurre durante el proceso de revisión y aprobación del texto constitucional final. Dedicamos un apartado a cada una de esas fases, pero esto último lo incluimos en el apartado sobre el establecimiento del transitorio.

\section{El nombramiento y la remoción: la potestad presidencial será según la Ley de Servicio Civil:}

El proyecto presentado por la Comisión Dictaminadora ${ }^{8}$ pretendió eliminar el mandato existente desde 1946, argumentando que como se emitiría una ley de servicio civil, resultaba innecesaria una referencia o inclusión constitucional al respecto9. La discusión inicial se centró en los 
dos primeros incisos del que sería artículo 140 de la nueva Constitución Política, relativo a las potestades del Presidente de la República conjuntamente con el respectivo Ministro de Gobierno.

Aunque luego se daría la discusión sobre la inclusión de un Título específico sobre el servicio civil, este momento requirió de los constituyentes su mayor atención, así como adoptar una posición sobre la inclusión o no del enunciado constitucional, a partir de la moción de la fracción socialdemócrata para que los incisos 1) y 2) se leyeran respectivamente:

“1) Nombrar y remover libremente a los miembros de la fuerza pública, y los que sirvan cargos de confianza y a los demás que determine, en casos calificados, la Ley de Servicio Civil”

"2) Nombrar y remover, con sujeción a los requisitos prevenidos por la Ley de Servicio Civil, a cualquiera de los restantes servidores de su dependencia”.

Nótese que no se incluyeron dos aspectos de gran relevancia contenidos en la letra constitucional vigente a partir de 1946. El primero que dicho Estatuto debía ser emitido con la aprobación de dos tercios de los miembros del Poder Legislativo. El segundo, que no podría ser factor para el nombramiento o causa de destitución, las ideas políticas o sociales de la persona, lo que temporalmente significó un retroceso en las libertades democráticas.

Contra la propuesta socialdemócrata, otros diputados pretendían no aludir al servicio civil en la nueva Constitución. Quienes estaban identificados con la reforma social vigente y no derogada, consideraban un retroceso para el desarrollo político del país que el asunto se omitiera, pues la reforma de 1946 ya era un logro importante.

La decisión sobre el primer inciso requirió dos votaciones, ya que la primera resultó empatada. Debe tenerse en cuenta que el servicio civil era un objetivo de consenso de casi todos los sectores políticos, incluso de quienes fueron marginados de integrar la Asamblea Constituyente, por lo que sus opositores realmente no tenían tanta influencia política como podría parecer del resultado de la votación que casi lo frustra. El empate requirió que continuara discutiéndose para realizar otra votación en la siguiente sesión.

Los socialdemócratas habían incluido en la propuesta de Constitución descartada, todo un articulado relativo al funcionamiento del servicio civil, por lo que en ese tema, como en otros fundamentales para la modernización del estado, se manifestaba el enfrentamiento entre las 
posiciones conservadoras y reformadoras. La tarea de Rodrigo Facio, Rafael Carrillo y Fernando Fournier, quienes fueron los mayores impulsores, sería convencer a los demás diputados de su propuesta, en medio de procesos de negociación y acuerdo.

El impulso de cambios institucionales por la Junta de Gobierno, vino a engrosar el rubro de gastos en la planilla de empleados públicos. Por supuesto que los nombramientos de esos servidores se realizó al estilo normal de la época cuando se producía un cambio de gobierno: según las preferencias de los nuevos gobernantes. Con mayor razón por la situación creada como consecuencia del levantamiento armado.

Los críticos tuvieron argumentos para señalar abusos en la distribución de puestos, asunto que no era nuevo en la politiquería nacional, así como la supuesta proliferación de nuevas instituciones. Aludían constantemente a la posible permanencia en sus puestos de los servidores públicos nombrados por la Junta de Gobierno, luego de concluido el período del compromiso; así como a las posibilidades que tendría don Otilio, de nombrar cuando asumiera su cargo como Presidente de la República, a "personas de su confianza", asunto argumentado como una necesidad de reorganizar la administración pública para ajustar el presupuesto.

Por lo anterior la creación del servicio civil debía ser mediada por una forma de institucionalizar un reparto de puestos entre ambos sectores políticos, de manera que se diera continuidad entre un gobierno y otro a la permanencia de sus partidarios, lo que visto desde la perspectiva actual, parece haber sido una previsión para que luego no pudieran ser desalojados por la eventual emergencia de otra corriente política.

Además se requería un cuerpo de funcionarios que hicieran posible la continuación de la reforma social, heredada del "calderocomunismo", pero complementada con los cambios institucionales, que la Junta de Gobierno (o Partido Socialdemócrata) había iniciado a desarrollar y que continuaría en las décadas posteriores.

Que se trataba de una continuidad en el proceso de reforma no podía ser reconocido directa o conscientemente. Persistía una atmósfera muy crítica y negativa hacia los gobernantes anteriores, pues aunque no estaban físicamente presentes en el recinto deliberativo, eran aludidos reafirmando que habían sido desalojados del poder por la fuerza de las armas y que por los supuestos desmanes cometidos, carecían de méritos para regresar al poder político y al ejercicio del servicio público.

Un sectorde diputados criticaba constantementelos desmanes de la época del “calderocomunismo”, 
pero también el gran crecimiento de la burocracia durante la Junta de Gobierno. El diputado Ricardo Esquivel, uno de los más férreos opositores al enunciado constitucional, al referirse a la moción socialdemócrata sobre la inclusión de los cargos en la Ley de Servicio Civil, señalaba:

“... para nadie es un secreto el desarrollo enorme de la burocracia bajo la actual Junta de Gobierno. Es de imperiosa necesidad ajustar el Presupuesto a la realidad económica del país. Será esa una de las tareas fundamentales que tendrá que asumir de inmediato el próximo gobierno. De prosperar la moción en debate, consideramos que desde ahora estamos entrabando la marcha del gobierno que se habrá de iniciar el 8 de noviembre, el cual no tendrá la libertad que necesita para llevar a cabo sus planes de reorganización fiscal"

El gobierno de don Otilio Ulate heredaría la institucionalidad modernizadora del Estado, pero controlada por servidores nombrados por la Junta de Gobierno. Esto sería un frente de poder que no era del gusto de la mentalidad tradicional no acostumbrada a una presencia pronunciada de instituciones públicas. Además los servidores públicos tendían a convertirse en un sector social importante, con mayor razón si se consolidaban en sus puestos.

El mantenimiento de la institucionalidad social reformista y populista, implicaba un reconocimiento de la importancia de la calidad de vida de la población para lograr el crecimiento y la diversificación económica. El desarrollo capitalista requería mano de obra capacitada, educada y saludable, satisfecha del régimen político y con ingresos proporcionados a las necesidades de reproducción y mejora de las condiciones de vida. Con esta estrategia no se generarían focos de descontento, sino el soporte social para la ampliación del proceso, lo que aseguraría que los sectores políticos que habían emergido a la palestra con la Junta de Gobierno, asumirían el control político del país durante décadas hacia el futuro.

Al someterse de nuevo a votación, los socialdemócratas se apuntarían una victoria fundamental para la consolidación del servicio civil, al lograr la mayoría por el texto del inciso uno que propusieron. El resultado sería de 28 diputados a favor y 15 en contra, habiendo dos ausencias, lo que no solo reveló la influencia de la bancada socialdemócrata, que por supuesto estaba soportada también por la Junta de Gobierno. Evidenció también que el Partido Unión Nacional no era monolítico en temas que podrían afectar su poder al concluir el periodo de la Junta de Gobierno en favor de don Otilio. Además es posible que en los intermedios se dieran procesos de 
negociación y acuerdo, que no necesariamente se revelan en las actas de las sesiones.

Luego de ese desempate, los diputados Fournier, Arroyo y Acosta Jiménez presentaron la moción para votar el inciso dos, siendo aprobada sin más discusión.

\section{La creación del Título XV Constitucional.}

Los socialdemócratas se asegurarían de dar un rango mayor a la existencia de la institución, incluyendo un título propio en la Constitución, de la misma manera que se estaba haciendo con otras que modificaban el aparato estatal.

El texto lo propusieron en tres artículos que fueron los siguientes:

“Primero.- Un estatuto de servicio Civil regulará las relaciones entre el Estado y los servidores públicos, con el propósito de garantizar la eficiencia de los servicios, los cuales serán desempeñados con un criterio técnico y por el personal estrictamente necesario.

Segundo.- Con las excepciones que esta Constitución y el Estatuto de Servicio Civil determinen, los servidores públicos serán nombrados a base de idoneidad comprobada y sólo podrán ser removidos de sus puestos por las causales de despido justificado que expresa la legislación de Trabajo, o en el caso de reducción forzosa de servicios, ya sea por falta absoluta de fondos o para conseguir una más eficaz y económica organización de los mismos. Cuando no les esté vedado por esta Constitución, los servidores públicos pueden ejercer actividades electorales, excepto durante las horas de trabajo, y no podrán ser perjudicados por su independencia política.

Tercero.- Toda reforma el Estatuto de Servicio Civil requerirá la aprobación de las dos terceras partes del total de los miembros de la Asamblea Legislativa.”

A pesar de la discusión efectuada a propósito de los deberes del Ejecutivo sobre los nombramientos de los servidores públicos, al presentarse esta propuesta de nuevo se manifestó la oposición de un sector importante de constituyentes, por ejemplo el diputado Esquivel lo consideraba innecesario y reglamentista. Pero Carrillo de nuevo expresó que por el transitorio aprobado, la creación del servicio civil no afectaría la reorganización proyectada por el próximo gobierno, señalando además que se trataba de una realidad para Costa Rica.

En primer lugar se aprobó la creación de un nuevo título que se denominaría “El Servicio Civil”. Luego se votaría cada uno de los artículos. 
El representante Ortiz se oponía indicando que no estaba bien que un solo estatuto cobijara a todos los empleados públicos, sino que debían ser varias leyes de ese tipo, como era el caso de los maestros, que estaban asociados a la ANDE. ${ }^{10}$ Lo anterior además de una proliferación innecesaria de la burocracia, sin embargo se pronunció por que se establecieran varios estatutos según los gremios.

El diputado Otón Acosta Jiménez, de Unión Nacional, señalaba la necesidad del artículo primero para indicar la esencia de lo que sería el servicio civil, abogando por la necesidad de un respaldo constitucional, ya que de otra manera no se daría fin a las prácticas viciosas del pasado. El socialdemócrata Fournier señaló que otras constituciones modernas como las de Cuba, Guatemala y Panamá ya tenían ese enunciado constitucional. Carrillo reforzó la posición a favor por la necesidad de que constitucionalmente se indicara lo esencial del servicio civil y cómo debían ser nombrados y removidos los servidores públicos.

El artículo primero sería aprobado con una modificación propuesta por el diputado González Herrán, que eliminó la última frase, por considerar que sobraba. De esa manera el primer artículo del Titulo sobre el servicio civil, que sería el 191 constitucional, quedó de la siguiente manera:

"Un estatuto de servicio Civil regulará las relaciones entre el Estado y los servidores públicos, con el propósito de garantizar la eficiencia de los servicios”.

El siguiente artículo fue defendido por el diputado Fournier reiterando los contenidos sobre el nombramiento y remoción. El texto fue aprobado luego de modificarse de la siguiente manera:

“Con las excepciones que esta Constitución y el estatuto de servicio Civil determinen, los servidores públicos serán nombrados a base de idoneidad comprobada y sólo podrán ser removidos de sus puestos por las causales de despido justificado que expresa la legislación de Trabajo, o en el caso de reducción forzosa de servicios, ya sea por falta absoluta de fondos o para conseguir un más eficaz y económica organización de los mismos”.

Nótese que en el texto aprobado se eliminaron las frases propuestas originalmente, referidas a la libertad de realizar actividades electorales fuera de la jornada laboral y que los servidores no podrían ser perjudicados por su independencia política. Esto último también tiene relación con la eliminación de la frase establecida con la reforma constitucional efectuada en 1946, respecto a 
los nombramientos o remociones considerando las ideas políticas o sociales de las personas.

Si bien este tema parece desapercibido de la discusión de los diputados, no deja de llamar la atención que fuera importante con posterioridad, incluso al emitirse el Estatuto de Servicio Civil, ya que según el artículo 50 del mismo, los servidores que en ese momento estaban nombrados quedaron de pleno derecho protegidos sin llenar los requisitos para el nombramiento, lo que evidentemente les favorecía, al no tener que aplicar y aprobar las pruebas del proceso de selección. Pocos años después, los simpatizantes socialdemócratas también serían beneficiados mediante la ley número 1918 del 3 de agosto de 1955, que ordenó el otorgamiento de puntos adicionales a las calificaciones obtenidas, a los participantes en la defensa del segundo gobierno de Don Pepe durante la intentona de Calderón Guardia de 1955. Se obligaba además al Departamento de selección de personal, a incluir al menos a un excombatiente en las ternas o nóminas para efectuar los nombramientos, si los había entre los candidatos elegibles.

El tercer artículo no fue aceptado por la mayoría de diputados, a pesar de la defensa sobre la necesidad de que la ley de servicio civil no fuera de fácil modificación. Esto también estuvo contenido en la reforma de 1946.

El diputado Volio Sancho propuso otro artículo que completaría el Titulo del Servicio Civil, que fue aprobado y dice lo siguiente:

"El Presidente de la República, los Ministros de Gobierno y los funcionarios que manejen fondos públicos, están obligados a declarar sus bienes, los cuales deben ser valorados, todo conforme a la ley".

Su argumentación se dio en el sentido de establecer constitucionalmente cuáles funcionarios deberían estar obligados a declarar sus bienes, con el fin de evitar los peculados cometidos en las administraciones anteriores. Refirió asimismo la existencia de tales postulados en constituciones modernas, para lo que aludió específicamente a la de Guatemala.

\section{El transitorio: mecanismo para consolidar el reparto del botín:}

El transitorio a los incisos primero y segundo del artículo 140 lograría una confluencia de intereses entre los opositores al servicio civil y los reformadores. La consolidación en los puestos, que popularmente se conocería como adquirir la "propiedad", no ocurriría de manera inmediata. Se buscaba no afectar al gobierno entrante de Otilio Ulate, para que sus representantes en la Asamblea Constituyente no tuvieran porqué oponerse. 
El Diputado FOURNIER lo presentó con la propuesta siguiente:

“La Ley de Servicio Civil deberá entrar en vigor no antes del 8 de noviembre de 1950 ni después del $1^{\circ}$ de junio de 1953, según lo disponga la Asamblea Legislativa. Esa ley podrá, además, disponer que sus normas se vayan aplicando gradualmente a los diversos departamentos de la Administración Pública; en todo caso, dicha ley deberá cubrir a la totalidad de los servidores públicos incluidos en el inciso 2) a más tardar el 8 de noviembre de 1959.

En tanto no entre en vigencia la ley de Servicio Civil, el Presidente y el respectivo Ministro de Gobierno podrán nombrar y remover libremente a todos los servidores públicos de su dependencia”

No hubo mayor discusión y se aprobó. Eran aspectos que se habían considerado y acordado al definirse los textos de los incisos uno y dos del artículo 140. La gradualidad del proceso en la cobertura de los servicios públicos, respondía a una consideración de la maduración de esta institución, conforme "se estime conveniente para el país", tal como la había indicado don Rodrigo Facio:

“... una ley de esta naturaleza es muy compleja y no puede promulgarse de un momento a otro, o de un solo golpe. Es necesario irla adaptando poco a poco a la realidad y conveniencias nacionales...

... en el proyecto del 49 fuimos lo suficientemente flexibles en esta materia, ya que reconocemos que el país no cuenta con la experiencia necesaria para que sea promulgada, violentamente, una ley de Servicio Civil ... el hecho de que desde ahora se dejara consignado en la nueva Constitución el requisito indicado, no iba traer ningún conflicto. La institución queda en teoría. Su aplicación vendrá a la emisión de la ley, la cual, de todos modos, se aplicará en una forma gradual... “

Sin embargo durante el periodo de revisión del texto constitucional, posterior a la discusión y definición de todo el articulado, al llegar al transitorio sobre la vigencia de la ley de servicio civil, un grupo de 28 diputados presentó una moción para que el segundo párrafo se leyera del modo siguiente: 
“Mientras no entre en vigencia la Ley de Servicio Civil, el Presidente de la República y el Respectivo Ministro de Gobierno podrán nombrar y remover libremente a todos los servidores públicos de su dependencia, incluso a los Directores y Gerentes de las Instituciones Autónomas y a los integrantes de las Juntas u organismos oficiales, cuyos nombramientos hubieren sido hechos con anterioridad a la fecha de vigencia de esta Constitución, aun cuando tales designaciones lo fueren por periodo fijo; y al efecto, decláranse interinos tales nombramientos. El ejercicio de las facultades que por este Transitorio se otorgan al Poder Ejecutivo no hará incurrir al Estado en responsabilidad de ninguna clase, ni en la obligación de pagar las prestaciones legales por despido de empleados o de funcionarios, cuyas dotaciones pasen de la suma de $\$ 600.00$ (seiscientos colones)".

La propuesta sugiere que de otra manera los directores y gerentes no serían removidos y es clara la intención de violar las obligaciones laborales, liberando al Estado del pago de las prestaciones legales. Pero además la referencia a esos funcionarios, parece indicar la necesaria competencia técnica para el desempeño de esas responsabilidades, así como que dichos servidores deberían estar cubiertos de los vaivenes políticos ${ }^{11}$.

Se produjo una larga discusión, que revelaría la presencia de intereses divergentes entre los representantes de la Junta de Gobierno, básicamente los socialdemócratas, y quienes fungirían como voceros del gobierno entrante de don Otilio Ulate. El asunto tenía gran trascendencia para ambas partes, incluso con sentimientos de agravio que pusieron en peligro la aparente tranquilidad y acuerdo que se había mantenido.

El Diputado Volio Sancho indicó que la armonía y acuerdo se rompería provocando perturbaciones políticas, y que no podían ser pasivos viendo que

“... a los actuales funcionarios públicos se les trate como si fueran "mariachis”. No es eso justo. Esta bien que una medida como la que se propone la pusiera en práctica la Junta al asumir el Poder, por las razones que de sobra conocemos los costarricenses, pero no ocurre lo mismo en las actuales circunstancias. Se desea dejar la puerta abierta para echar a la calle a los servidores públicos como si se tratara de los delincuentes del régimen anterior... ” 
Coincidía con Rodrigo Facio en que se pretendían desconocer los derechos laborales, señalando además que se trataba de quienes combatieron en la "gran lucha de liberación nacional” y que

"No sería natural que se correspondiera de ese modo a quienes le han prestado a la patria tan útiles servicios. Además, la medida vendrá a constituir un pésimo precedente con respecto a las Instituciones Autónomas, ya que se permite al Ejecutivo meter la mano en el sistema de ellas, comprometiendo su estabilidad..."

Sobre esto último el diputado Fernando Baudrit, quien además era el rector de la Universidad de Costa Rica, señaló que si lo pretendido era afectar la autonomía de las instituciones, "no tenga cuidado alguno el futuro Ministro de Educación; allí le quedará mi puesto de Rector sin preavisos ni cesantías si en la Universidad ha de meter sus manos lo oficial, nada tendría que hacer yo en la Institución”.

Diputados como González Flores y Leiva Quirós defendían la propuesta alegando motivos de equilibrio presupuestario, para que el gobierno no pagara indemnizaciones por varios millones de colones.

Rodrigo Facio, aludiendo a la gran cantidad de firmas que suscribían la propuesta, le señaló errores, así como el "carácter odioso que demuestra" y lo innecesario del texto. Entre otros aspectos, el derecho constitucional de los trabajadores a una indemnización en caso de despido sin causa justa y lo indicado en el aprobado Titulo XV relativo al servicio civil. Se había establecido además la posibilidad de despidos para lograr una mejor organización administrativa. Desde ese momento es posible señalar que el servicio civil no se establecía para que los servidores públicos fueran inamovibles.

Además de otros argumentos, Facio aludió el editorial del diario nacional La Prensa Libre del 18 de octubre de 1949, que había señalado la falta de madurez en la propuesta, ya que se prestaba para una maniobra política en detrimento del establecimiento del servicio civil en Costa Rica, pues "siempre quedará empotrado a las contingencias políticas”. Es decir la misma Asamblea Constituyente se estaría contradiciendo al establecer una institución de gran importancia para el futuro del país, pero que la mediatizaba en decisiones de trascendencia, como era el nombramiento o la destitución de los servidores.

Aunque la propuesta fue votada y aprobada, al día siguiente los diputados Rodrigo Facio y Volio 
Sancho solicitaron revisión del acuerdo tomado, indicando el señor Facio que la votación anterior pareció ser resultado de una decisión tomada "sin consideración alguna". Sin embargo los proponentes del cambio en el transitorio reiteraban los argumentos sobre la situación caótica de la hacienda pública, los organismos innecesarios y "funcionarios públicos que han desempeñado puestos innecesarios con dotaciones elevadísimas” a quienes se les pagaría sus indemnizaciones. El diputado Esquivel se refirió a la información dada a conocer por los periódicos durante ese día, sobre la amenaza de renuncia de la Junta de Gobierno si el mencionado transitorio se mantenía, no obstante esperaba que a pesar de ello la Asamblea mantuviera lo aprobado en la sesión anterior. Señaló también el bajo componente de los servidores con salarios menores a los seiscientos colones: de

"trece mil doscientos noventaynueve (13.299) empleados de la Administración Pública, doce mil seiscientos trece (12.613) devengan sueldos menores de seiscientos colones (600.00). Sólo seiscientos ochenta y seis ganan sueldos superiores. Es decir, con el transitorio quedan garantizados más del noventa y cuatro por ciento de los empleados de la Administración.

Volio Sancho informó que debido a la declaración como interinos, casi todos los gerentes de las instituciones habían presentado sus renuncias, pues les resultaba humillante. Más directo el diputado Monge Alvarez, además de calificar el texto como "el monumento más grande de inmoralidad que pueda haber aprobado la Asamblea Nacional Constituyente”, así como de atropello de la dignidad y de los derechos laborales, hizo referencia a otros elementos:

“... En el fondo no es más que una miserable venganza política. Criticamos mucho en Costa Rica el servilismo de los empleados hacia sus gobernantes. Censuramos esa falta de honradez de los mismos. Y con ese transitorio venimos a decir ahora que si no se doblegan ante determinados grupos políticos tendrán que irse a la calle. Conozco a don Otilio Ulate muy bien y estoy seguro que él no querrá empleados con espinazo de hule. Quien predicó la honestidad administrativa, el derecho de los empleados a pensar como a bien lo tuvieran, no puede estar de acuerdo con una medida que da por tierra con todos esos principios. Con ese transitorio se les está señalando a los empleados como si fueran delincuentes. No otra cosa se está haciendo al declararlos en interinidad y negarles sus prestaciones legales ... gobiernos inescrupulosos, como los de Calderón y Picado, no habían llegado hasta el extremo de meter sus manos en las instituciones autónomas ...” 
Rafael Carrillo retomó algunos de los argumentos ya expresados por sus colegas y reafirmó su rechazo en términos que sintetizan la posición socialdemócrata:

“... Primero.- No merece el Gobierno de don José Figueres que se desconozcan los legítimos derechos de sus funcionarios; porque no solamente restableció ese gobierno las libertades públicas e hizo posible el retorno a la normalidad constitucional y el respeto a la voluntad popular, sino que se caracterizó por un exquisita probidad y por una cuidadosa selección de personal administrativo, habiendo realizado en este último aspecto una labor sin precedente. Segundo.- La medida es atentatoria al principio de respeto al funcionario público, sin el cual no podrá existir en el futuro la institución del servicio civil. Tercero.- La interinidad, declarada por canon constitucional, será permanente para todos los servidores nombrados antes de entrar en vigencia la nueva Constitución; al no fijar el transitorio un término para la remoción, quedan expuesta a ella los actuales servidores públicos, por tiempo indefinido y sin derecho a indemnización. Cuarto.- Al incluirse en la interinidad a los directores y gerentes de las instituciones autónomas, además de que se pone en serio peligro la estabilidad de esas instituciones y se viola su régimen jurídico, se establece el funesto precedente de colocarlas bajo la acción política inmediata del partido de gobierno, con las fatales consecuencias que necesariamente se han de derivar de tan absurdo procedimiento".

Vargas Fernández recriminó a Luis Alberto Monge, recordando la discriminación de que habían sido objeto los servidores públicos del gobierno de Teodoro Picado, ya que a muchos se les despidió sin reconocérseles sus derechos y no se les pagaron los últimos meses trabajados, mientras con la medida propuesta solo se afectaría a los altos funcionarios.

El acuerdo se logró mediante la votación de una propuesta hecha por el diputado Numa Ruiz, que conciliaba las posiciones eliminando la alusión a la interinidad y al no pago de las prestaciones legales. El segundo párrafo del transitorio sobre la entrada en vigencia de la ley de servicio civil quedó de la siguiente manera:

"Mientras no entre en vigencia la ley de servicio civil, el Presidente de la República y el respectivo Ministro de Gobierno podrán nombrar y remover libremente a todos los 
funcionarios de su dependencia, incluso a los directores y gerentes de las instituciones autónomas y a los integrantes de las Juntas u organismos oficiales, cuyos nombramientos hubieren sido hechos con anterioridad a la fecha de vigencia de esta Constitución, aun cuando tales designaciones lo fueren por periodo fijo."

Al emitirse el Estatuto de Servicio Civil en 1953, quienes ocupaban sus puestos fueron declarados “en propiedad”, sin acudir a la demostración por exámenes o concurso público, en un proceso de declaración formal de idoneidad que legalizaba tal procedimiento. ${ }^{12}$

\section{CONCLUSIONES:}

Los miembros de la Asamblea Constituyente de 1949, tenían un claro bagaje conceptual sobre el significado y trascendencia del servicio civil para Costa Rica, que se debía a la observación durante varias décadas del reparto de puestos públicos por los gobiernos de turno entre los partidarios políticos. Se conocía la experiencia de países europeos y americanos y sus impulsores eran intelectuales destacados del ámbito político y académico, con amplia formación y experiencia académica y en el análisis de los problemas nacionales. Esto posibilitó una claridad de objetivos en el momento que este tema fue discutido en el seno de la Asamblea Constituyente, logrando mantener y ampliar el rango constitucional de los principios del régimen de servicio civil, particularmente en lo que se refiere al nombramiento y remoción de los empleados públicos.

La consolidación del rango constitucional del régimen de servicio civil en Costa Rica ocurre como parte de un proceso de modernización económica del país, que es impulsado por una nueva tendencia política que triunfa en la guerra civil de 1948. El control del aparato estatal abrió espacios políticos y económicos para la emergencia de nuevos sectores de burguesía nacional, que requerían condiciones que posibilitaran otros espacios de acumulación de capital. Era necesario que las instituciones públicas contaran con recursos humanos profesionalmente capaces para el desarrollo de diversos programas, requeridos para el crecimiento económico y la estabilidad social en campos como educación, la salud y la vivienda. Esto a su vez implicaba tecnificar la función pública, mediante la evaluación para el ingreso y la remoción por causas justificadas, lo que no podía lograrse con los vaivenes que ocasionaban los cambios de gobierno.

En el marco de un clima de confrontación social, se manifiesta la exclusión y aislamiento de 
las fuerzas políticas predominantes durante la década de 1940. Con la situación creada luego de la guerra civil y el establecimiento del gobierno de facto, se les impidió la participación electoral y por lo tanto no tuvieron representación en la Asamblea Constituyente. A pesar de esto, la mayor parte de los avances sociales y políticos se mantuvieron o se fortalecieron en la nueva Constitución Política emitida en 1949, incluyendo los postulados constitucionales sobre el servicio civil.

Habiéndose relegado y a los comunistas y calderonistas, afloraron otras contradicciones, básicamente entre las fuerzas emergentes y las tradicionales. Las primeras representadas en la Asamblea Constituyente por la fracción del Partido Socialdemócrata, que compartía su pensamiento con la Junta de Gobierno presidida por don José Figueres y contaba con el apoyo de un sector de diputados de otros partidos. Las segundas, voceras en lo fundamental del Partido Unión Nacional, representante del gobierno que iba a suceder a esa Junta.

Con respecto al servicio civil las contradicciones ocurrían alrededor de las consecuencias que tendría en los puestos y servidores que habían sido nombrados por la Junta de Gobierno, quienes habían desplazado a los calderonistas y en su momento debían ser desplazados a su vez, por otros del gobierno entrante de Otilio Ulate. Esto se evidencia con la amenaza de renuncia de la Junta de Gobierno, al ser discutido el texto del transitorio que pretendió declarar interinos a los servidores y, en caso de ser despedidos por el gobierno de Ulate, no pagarles los derechos laborales.

Las propuestas de los diputados que representaban a las fuerzas sociales emergentes resultaron en la inclusión, no solo de un mandato constitucional al Poder Ejecutivo para el nombramiento y remoción de los servidores públicos, sino de un Título dedicado a la existencia del Régimen de Servicio Civil en Costa Rica. Esto se vio favorecido por el hecho de que los socialdemócratas representaban al gobierno de facto, así como porque establecieron un pacto para mantenerse durante año y medio en el poder.

Mediante un acuerdo logrado durante la discusión constitucional, se pospuso la vigencia del Título sobre el servicio civil de la Constitución Política emitida en 1949. Esta postergación se extendió hasta el 30 de mayo de 1953, justo el día último que estableció la Asamblea Constituyente para emitir el Estatuto de Servicio Civil. El motivo argüido sería la necesidad de elaboración y maduración del proyecto, pero como hemos visto, tal maduración no lo era en términos conceptuales. Se trataba de una postergación de carácter estratégico, producto de la disputa por el control del aparato institucional del Estado. Para ello requerían de la presencia de 
los combatientes o herederos del 48 dentro de las filas de los servidores públicos, así como de los herederos del botín político propio de los caudillos de la época de los gamonales.

Los programas institucionales necesarios para sostener e impulsar nuevas fuentes de acumulación de capital, requerían una planilla de empleados públicos que los llevara a cabo. La posición de poder de la Junta de Gobierno posibilitó que los proyectos esbozados e iniciados no se detuvieran, a pesar de la renuencia de la oligarquía tradicional para apoyarlos. La consolidación del proceso requería del régimen de servicio civil, como un soporte fundamental para dar estabilidad y continuidad técnica a esos programas, lo que implicaba necesariamente una distribución de cuotas de poder con los opositores oficiales del momento a la Junta de Gobierno, ya que eran dominantes en la Asamblea Constituyente y además, asumirían el poder a partir de noviembre de 1949.

\section{NOTAS}

1 Citado en Volio, Marina. Jorge Volio y el Partido Reformista. San José, Ed. Costa Rica, 1973, página 104.

2 Citado por De La Cruz, Vladimir. Las luchas sociales en Costa Rica 1870-1930. San José, Ed. Costa Rica, 1980, página 251.

3 Citado en una de sus disertaciones en defensa de la creación del servicio civil, por el Diputado Constituyente don Rafael Carrillo.

$4 \quad$ El señor González Herrán fue miembro del Tribunal de Honor al fundarse el Partido Social Demócrata. Don León Cortés fue Presidente de la República entre 1936 y 1940. La alusión de dicha ley está indicado de esa manera en las Actas de la Asamblea Constituyente de 1949, pero es posible que se tratara de un reglamento de ámbito municipal, ya que en esa época tales normas eran emitidas por el Presidente de la república.

5 Se trata de un grupo cívico al que se le conoció como “Grupo Coronas”, por don Ángel Coronas, uno de sus más connotados miembros. Como resultado de la encuesta publicaron el "Ideario Costarricense”, que recoge las opiniones sobre un conjunto de problemas nacionales de la época, de muchos ciudadanos que fueron opositores al gobierno del Doctor Calderón Guardia. Entre quienes dieron su opinión estaba Don Pepe Figueres, quien envió sus respuestas desde el exilio en México, en la que también señalaba la necesidad de implantar lo más pronto posible "el tecnicismo profesional y el servicio civil en todos los organismos administrativos en sustitución del empirismo y del compadrazgo.”

$6 \quad$ Citados por el diputado Rafael Carrillo.

$7 \quad$ Don Róger Fallas Barrantes hace un paralelo entre los textos del proyecto de don Oscar Barahona Streber y el Estatuto aprobado en 1953, que evidencia este aspecto. Véase: Fallas Barrantes, Róger. "El Proyecto Barahona Streber”. En: 35 aniversario del régimen de servicio civil 1953-1988. San José, sf, Imprenta Nacional. 


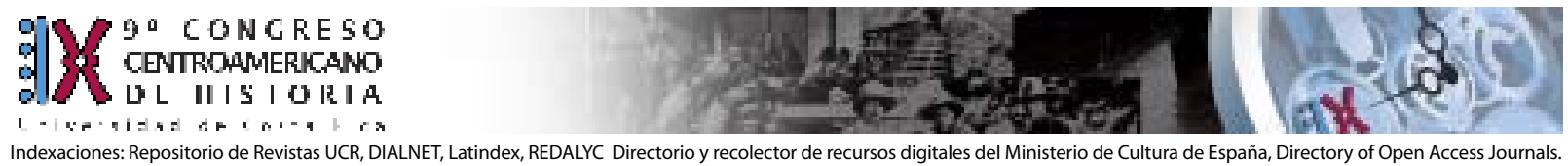

Indexaciones: Repositorio de Revistas UCR, DIALNET, Latindex, REDALYC Directorio y recolector de recursos digitales del Ministerio de Cultura de España, Directory of Open Access Journals. Diálogos Revista Electrónica de Historia ISSN 1409-469X. Número especial 2008. Dirección web: http://historia.fcs.ucr.ac.cr/dialogos.htm

8 Recordamos que el proyecto presentado por la Junta de Gobierno, cuyo conocimiento era el motivo de la elección de la Asamblea Constituyente, fue descartado y en su lugar se integró una Comisión Dictaminadora que decidió proponer otro proyecto redactado con base en la Constitución vigente desde 1871.

9

En efecto, la Junta de Gobierno emitió un Estatuto de Servicio Civil mediante el Decreto Ley Número 795, del 2 de noviembre de 1949, pero la vigencia en el marco del Transitorio al que nos referimos más abajo, sería a partir del momento que determinara la Asamblea Legislativa. Además se emitió en los últimos días de la Junta de Gobierno. Como resultado este Estatuto nunca entró en vigencia.

10 No muy lejos estaba el señor Ortiz de lo que sería la realidad, pues luego se emitirían distintas leyes que paulatinamente separarían la aplicación del Estatuto de Servicio Civil emitido en 1953 de otras instituciones públicas y gremios, las que tendrían su propia normativa para los procesos de nombramiento y remoción de los empleados. De esa manera hay quienes consideran que, dada la similitud de esas leyes, en Costa Rica existe un servicio civil pero con diversos regímenes de empleo. Hay normas particulares para buena parte de las instituciones autónomas y para ciertos gremios particulares.

11 Tal condición es contraria a la situación actual que ha colocado dichos cargos a la disposición de los jerarcas ministeriales, ya que mediante una reforma de hace algunos años fueron declarados de confianza, lo que implica no solo su libre remoción, sino también que el acceso a ocupar tales cargos ocurre por la afinidad con los jerarcas y no mediante la carrera administrativa o el mérito determinado mediante las evaluaciones respectivas. En 1949 se consideraba que esos puestos eran técnicos y debían alcanzarse mediante la carrera administrativa.

12 Desde la creación material del régimen de servicio civil, se han establecido mecanismos legales que a través de décadas han definido el ingreso de muchos servidores públicos de programas completos, sin recurrir a los procedimientos de concurso público externo, que es el principio enunciado tan temprano como lo es 1825. Tales ingresos han sido asumidos por el presupuesto nacional sin que hayan cumplido los requerimientos establecidos para puestos de la misma clasificación, lo que significa que no han cumplido los requerimientos de idoneidad. Esto contradice lo que defendieran con tanta vehemencia los eminentes constitucionalistas Rodrigo Facio, Rafael Carrillo y Fernando Fournier cuando lograron la creación del servicio civil en 1949.

\section{BIBLIOGRAFIA}

Aguilar, Marielos. Carlos Luis Fallas: su época y sus luchas. San José, Editorial Porvenir, 1983.

Bolaños González, Jimmy. Estatuto de Servicio Civil. (Comentado, con jurisprudencia y legislación conexa). San José, Ed. Investigaciones Jurídicas, 2003.

Cerdas Albertazzi, José Manuel y Contreras, Gerardo. Los años 40`s: historia de una política de alianzas. San José, Ed. Porvenir. 1988.

Contreras, Gerardo. La historia no es color de rosa. A propósito de los setenta y cinco años del Partido Comunista de Costa Rica. San José, Ed. Perro Azul, 2006.

De La Cruz, Vladimir. Las luchas sociales en Costa Rica 1870-1930. San José, Ed. Costa Rica, 1980. 
Fallas Barrantes, Róger. "El Proyecto Barahona Streber”. En: 35 aniversario del régimen de servicio civil 1953-1988. San José, Imprenta Nacional, sf.

Ferreto, Arnoldo. Gestación, consecuencias y desarrollo de los sucesos de 1948. San José, Ed. Zúñiga y Cabal, 1987.

Figueres Ferrer, José. El espíritu del 48. San José, Ed. Costa Rica, 1987.

Molina Jiménez, Iván. Demoperfectocracia: la democracia pre-reformada en Costa Rica (18851948). Heredia, EUNA, 2005.

Molina Jiménez, Iván y Lehoucq, Fabrice. Urnas de lo inesperado: fraude electoral y lucha política en Costa Rica: (1901-1948). San José, Editorial de la Universidad de Costa Rica, 1999.

Romero Pérez, Jorge Enrique. Acción Demócrata: orígenes del Partido Liberación Nacional (De León Cortés a José Figueres). San José, Ed. Nueva Década, 1983.

Rovira Mas, Jorge. Estado y política económica en Costa Rica 1948-1970. San José. Ed. Porvenir. 1982.

Volio, Marina. Jorge Volio y el Partido Reformista. San José, Ed. Costa Rica, 1973.

\section{PÁGINAS ELECTRÓNICAS CONSULTADAS}

http://www.elespiritudel48.org/ http://www.elespiritudel48.org/docu/docu.htm http://www.elespiritudel48.org/bio/bios.htm http://www.elespiritudel48.org/docu/testi.htm http://www.elespiritudel48.org/anexos.htm http://www.elespiritudel48.org/docu/actas/index.html http://www.elespiritudel48.org/4802.htm http://www.pgr.go.cr/scij/busqueda/normativa/normas/nrm repartidor.asp?param1=NRMA www.cesdepu.com/actas.htm http://www.cesdepu.com/actas/rsv50.doc http://www.cesdepu.com/actas/ANC49-131-140.pdf http://www.cesdepu.com/actas/ANC49-161-170.pdf http://www.cesdepu.com/actas/ANC49-171-180.pdf http://www.cesdepu.com/actas/diputados.doc http://www.cesdepu.com/actas/Proyecto\%20Gobierno\%20de\%20Facto.doc http://www.cesdepu.com/actas/const1871.doc http://www.cesdepu.com/actas/Proyecto\%20Comision\%20Redactora.doc http://www.monografias.com/trabajos11/areva/areva.shtml http://www.lexenesis.com/lexenesis/Paginas/historia/rev1944.htm http://www.lexenesis.com/lexenesis/Paginas/historia/pre35.htm 